\title{
ANALYSIS OF RAIN RATE AND RAIN ATTENUATION FOR EARTH-SPACE COMMUNICATION LINKS OVER UYO - AKWA IBOM STATE
}

\author{
I. E Afahakan'1, K. M. Udofia ${ }^{2, *}$ and M. A. Umoren ${ }^{3}$

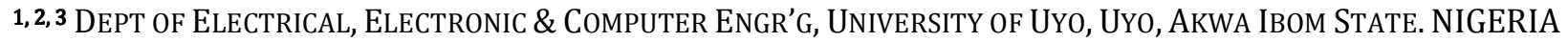 \\ E-mail addresses:1afahakani@yahoo.com,2,kmudofia@gmail.com,3mfon4gigis@yahoo.com
}

\begin{abstract}
Rain rate and rain attenuation predictions are vital when designing microwave satellite and terrestrial communication links, such as in the $\mathrm{Ku}$ and $\mathrm{Ka}$ bands. This paper presents the cumulative distribution functions (CDFs) of the predicted rain rate and rain attenuation for Uyo, Akwa Ibom State (AKS) (Latitude: 4.88\%, Longitude: $8.09^{\circ}$ E, Height above Sea Level: $51.2 \mathrm{~m}$ ), a typical rain forest zone in Nigeria, using rainfall data for three years spanning between January 2010 and December 2012. These measurements were recorded by the meteorology department of the Akwa Ibom International Airport (AIIA), Uyofor percentage availabilities 99.9 to 99.999. Rainrate measurements were carried out using the Moupfouma and Chebil models - models purposely designed for tropical zones, while the International Telecommunications Union Radio-wave propagation (ITU-R P) models were used for estimating rain-attenuation. The results obtained will serve as a good preliminary design tool for both terrestrial and earth-satellite microwave links.
\end{abstract}

Keywords: Rain Rate, Rain Attenuation, Propagation Impairment, Cumulative Distribution.

\section{INTRODUCTION}

The presence of rain along satellite-earth path is a major cause of signal attenuation at frequencies above $10 \mathrm{GHz}$ [1]. Raindrops absorb and scatter radio waves, resulting in signal attenuation, and in the reduction of the overall link availability. The severity of rain impairment increases with frequency, and varies with climates[2]. It is therefore very important when planning both microwave satellite and terrestrial lineof-sight links, to make an accurate prediction of rain induced attenuation [3]. Initially, attenuation prediction attempts involved extrapolation of rain attenuation measurements from specific locations to other locations using frequencies (frequency scaling), or elevation angles (elevation scaling) in [4]; however, the complex nature and regional variability of rainfall distributions make this approach highly inaccurate[5]. Several procedures exist for the prediction of rain attenuation on earth-space paths. These procedures can be grouped in two classes: empirical and physical. Empirical classes are based on measurement databases from stations in different locations within a given region; and physical classes attempt to reproduce the physical behaviour involved in the attenuation process [6].

Empirical method is more frequently used. It makes use of equations with variables, such as rain height, rain rate and earth-station latitude and longitude [1]. In empirical method, an appropriate distribution of rainfall rate at 1-minute integration time is needed for the site under study in order to predict accurately the rain attenuation for that location[7]. This is because rain rates obtained through longer periods of integration might fail to capture a high-intensity, short-duration rain event, and are not recommended for communication systems designs[1].

\section{REVIEW OF RELATED WORKS}

A few research works have so far been carried out to obtain a rainfall rate of 1-minute integration time necessary for the study of rain induced impairments of propagation signals, especially in a tropical country such as Nigeria. The locations in Nigeria (mostly in the South West) where results have been obtained previously include Ile-Ife, Osun State [8], Akure, Ondo State [9-11], Ota, Ogun State [12], Ogbomosho, Oyo State [13], Ilorin, Kwara State [14]. 
The rain in Nigeria is characterized by high intensity rainfall, high frequency of rain occurrence and the increased presence of large raindrops when compared with temperate climates[7]. The data used for these analyses were obtained from the Tropical Rain Measurement Mission (TRMM) jointly developed by the United States of America (USA) and Japan, and also from the Global Precipitation Climatology Project (GPCP) on the World Climatic Research Programme (WCRP). However, these data cannot be employed directly in system design, due to its long integration time. Hence, methods that convert the available rain rate data to the equivalent 1 -minute rain rate cumulative distribution is necessary for the accurate prediction of rain rate, such methods include the ITU$\mathrm{R}$ [15] and model Crane Model [16] for rain-rate prediction. This paper presents estimates of rainfall rates at 0.001 to $0.1 \%$ of the time exceeded for an average year, and uses these values to estimate rain attenuation of microwave signals on earth-space path, and then make comparisons with the prediction in [15].

Rain-rate and rain-attenuation prediction have naturally attracted a great deal of attention as in research works carried out in the USA[17], Malaysia[18], Colombia [1],Nigeria [7, 19, 20]and on a global scale $[3,21]$.The rainfall rates rain attenuation at 0.001 to $0.1 \%$ of time exceeded for an average year and rain attenuation for AKS were obtained using Moupfouma [22] and Chebil [18] models designed for tropical zones. These models are a mix of the lognormal distribution of low rain rates and the gamma distribution for high rain rates, and ITU model for predicting rain attenuation [4].

Furthermore, efforts have been made by Ajayi and Ezekpo [23] and Omotosho and Oluwafemi [19]to obtain 1-minute rain rate map, and rain rate estimation respectively for Nigeria, using RiceHolmberg (R-H) model. The model is best behaved over the distribution, while the Moupfouma model performs suitably well, according to 0jo in [7]. Results for the rain rate exceeded for $0.01 \%$ of the time agrees with estimates for the cumulative rain rate distribution derived from higher integration-time statistics over this tropical site.

\section{RAIN RATE MODELS}

The point rain rate is the rain rate measured at a point using a single rain gauge, as opposed to being measured over the entire link. A procedure for the calculation of a cumulative rain-attenuation distribution from a point rain-rate distribution is therefore required if predictions are to be made. Several models exist that provide an estimation of the point rainfall-rate cumulative distribution.

Rice and Holmberg developed a model for obtaining rain rate values, after an analysis performed on measurements from stations inside and outside the USA, using the cumulative distributions of rain and maximum monthly period[24]. The result of the study is a point rain-rate cumulative rainfall accumulation, and a map of the highest rates expected for diurnal distribution based on a set of parameters obtained from the analysis of local rain accumulation data. Parameters include: the number of thunderstorm days expected in an average year ' $U$ '; the highest monthly precipitation observed in a set $\mathrm{M}_{\mathrm{m}}$; and the average annual accumulation $M$. The values of $U$ and $M_{m}$, are averaged over a 30-year period. This model has a universal acceptability, because it is based on local data. It uses long-integration-time of local rainfall data to determine the CDF of rain rates [1].

However, the rain rate distribution is better described by the model in[22] to be log-normally distributed at the low rain rates, and a gamma distribution at high rain rates. The model is best for both tropical and temperate climates, and can be expressed by Equation (1) as:

$$
P(R \geq r)=10^{-4}\left(\frac{R_{0.01}}{r+1}\right)^{b} e^{\left(u\left[R_{0.01}-r\right]\right)}
$$

Where $r(\mathrm{~mm} / \mathrm{h})$ represents the rain rate exceeded for a fraction of the time, $R_{0.01}(\mathrm{~mm} / \mathrm{h})$ is the rain rate exceeded at 0.01 percent of time in an average year, and $b$ is approximated by the expression in Equation (2):

$$
\mathrm{b}=\left(\frac{\mathrm{r}-\mathrm{R}_{0.01}}{\mathrm{R}_{0.01}}\right) \ln \left(1+\frac{\mathrm{r}}{\mathrm{R}_{0.01}}\right)
$$

The parameter $u$ in Equation (1) governs the slope of the rain rate cumulative distribution, and depends on the local climatic conditions and geographical features. For tropical and sub-tropical localities, $u$ is given in Equation (3) as

$$
\mathrm{u}=\frac{4 \ln 10}{\mathrm{R}_{0.01}} \mathrm{e}^{\left.\left(-\lambda \mid \frac{\mathrm{r}}{\mathrm{R}_{0.01}}\right]^{\gamma}\right)}
$$

where $\lambda=1.066$ and $\gamma=0.214$.

Thus, the Moupfouma model requires three parameters; $\lambda, \gamma$ and $\mathrm{R}_{0.01}$. While the first two parameters $\lambda$ and $\gamma$, have been provided. $R_{0.01}$, is estimated using the Chebil's model. This allows for the usage of long-time mean annual accumulation, $\mathrm{M}$, at the location of interest. 
The power law relationship of the model is given by Equation (4):

$$
\mathrm{R}_{0.01}=\alpha \mathrm{M}^{\beta}
$$

In (4), $\alpha$ and $\beta$ are regression coefficients defined as $\alpha$ $=12.2903$ and $\beta=0.2973$.

However, using the refined Moupfouma and Chebil model, the 1-minute rain-rate cumulative distribution can be fully determined from the long term mean annual rainfall data, and it is this model that is being used in this work, and then compared with the ITU model.

\section{RAIN ATTENUATION MODELS}

Ryde proposed a rain attenuation model in his paper published in [25], and cited in [26] three decades later. Crane applied measured data to Ryde's model to evaluate the average matching between model predictions and measurements. Based on further analyses, Crane proposed a new revised model called two-component model[27].

The ITU rain attenuation prediction model[4]presents good results which have close proximity to the average prediction of a set of results obtained from the application of eight different methodologies[22]. Hence, this research work makes use of this model for rain attenuation prediction.

\section{AIIA DATA}

The rainfall data used for this research were obtained from the Meteorological Centre at the AIIA, Uyo. The airport uses the tipping bucket range gauge, which is one of the meteorological measuring equipment connected to the Automatic Weather Observation System (AWOS) installed at the airport to obtain rainfall data. Rainfall data is automatically stored in two servers at a pre-determined time interval. Rainfall accumulation not up to a specified value in the interval measured was discarded. From these servers, the data is extracted into Microsoft Excel and that is what was obtained for processing. Three years of data spanning from January 2010 to December 2012 were recorded. The station parameters are latitude $4.88^{\circ} \mathrm{N}$, longitude $8.09^{\circ} \mathrm{E}$, and the height above sea level of $51.2 \mathrm{~m}$. A summary of the local climatology showing the rainfall accumulation at Uyo is presented in Table 1.

\section{ITU MODEL FOR POINT RAIN RATE DISTRIBUTION}

ITU-R recommendation P.837-6 [15] contains annexes and maps of meteorological parameters that have been obtained using the European Centre for MediumRange Weather Forecast (ECMWF) ERA-40 re-analysis database, which are recommended for the prediction of rainfall rate statistics with a 1-minute integration time, when local measurements are not available. The model uses a database of parameters (Pr6, Mt and $\beta$ ), available from the ITU's 3M Group[28], each of which is matched to a pair of longitude and latitude. This model was used to measure rain rate for comparison purposes and the result is presented in Figure 1.

Table 1: Statistics of rainfall accumulation for Uyo from January 2010 to December 2012

\begin{tabular}{|c|c|c|c|c|c|c|}
\hline \multirow[b]{2}{*}{ Month } & \multicolumn{2}{|l|}{2010} & \multicolumn{2}{|l|}{2011} & \multicolumn{2}{|l|}{2012} \\
\hline & $\begin{array}{l}\text { Total Volume of } \\
\text { Rainfall Per Month in } \\
(\mathrm{mm})\end{array}$ & $\begin{array}{l}\text { No. of } \\
\text { Rainy } \\
\text { days }\end{array}$ & $\begin{array}{l}\text { Total Volume of Rain } \\
\text { Per Month in (mm) }\end{array}$ & $\begin{array}{l}\text { No. of } \\
\text { Rainy } \\
\text { days }\end{array}$ & $\begin{array}{l}\text { Total Volume of } \\
\text { Rain Per Month in } \\
(\mathrm{mm})\end{array}$ & $\begin{array}{l}\text { No. of } \\
\text { Rainy } \\
\text { days }\end{array}$ \\
\hline January & 0.0 & 0 & 0.0 & 0 & 195.5 & 4 \\
\hline February & 0.0 & 0 & 82.0 & 6 & 290.1 & 10 \\
\hline March & 0.0 & 0 & 186.8 & 12 & 31.4 & 2 \\
\hline April & 0.0 & 0 & 175.2 & 7 & 150.9 & 14 \\
\hline May & 273.5 & 15 & 456.0 & 20 & 350.4 & 18 \\
\hline June & 711.3 & 22 & 466.5 & 21 & 689.4 & 21 \\
\hline July & 420.4 & 17 & 929.0 & 22 & 911.3 & 25 \\
\hline August & 682.9 & 21 & 407.9 & 24 & 697.7 & 19 \\
\hline September & 447.8 & 21 & 504.8 & 15 & 591.5 & 21 \\
\hline October & 308.7 & 18 & 561.9 & 20 & 498.9 & 14 \\
\hline November & 317.7 & 17 & 194.7 & 9 & 308.3 & 10 \\
\hline December & 10.5 & 1 & 4.0 & 1 & 2.9 & 3 \\
\hline $\begin{array}{l}\text { Total Volume of } \\
\text { Rainfall per Year }\end{array}$ & 3172.8 & 132 & 3968.8 & 157 & 4718.3 & 161 \\
\hline
\end{tabular}




\section{DEVELOPMENT OF POINT RAIN RATE DISTRIBUTION USING THE LOCAL CLIMATOLOGICAL DATA}

The point rainfall rate for Uyo was obtained using Moupfouma model which approximates a log-normal distribution at the low rates, and a gamma distribution at high rain rate, was combined with the Chebil's model. Thus, by combining Equations (1) to (4) and using the parameters in Table 1 as inputs, a 1minute rain-rate distribution shown in Figure 1 at $0.01 \%$ of time exceedance was obtained for each year. This is shown in Table 2.

Table 2: Summary of Results for Rain Rate and Rain Attenuation (for $20 \mathrm{GHz}$ ) Estimates at $0.01 \%$ of Time

\begin{tabular}{lcccc}
\multicolumn{5}{c}{ Exceedance. } \\
\hline Year & 2010 & 2011 & 2012 & Average \\
\hline $\begin{array}{l}\text { Total Vol of } \\
\text { rainfall (mm) }\end{array}$ & 3172 & 3968 & 4718.3 & 3953.3 \\
\hline $\begin{array}{l}\text { Number of } \\
\text { rainy days } \\
\text { Rain rate } \\
\text { (mm/hr) }\end{array}$ & 132 & 157 & 161 & 150 \\
\hline $\begin{array}{l}\text { Rain } \\
\text { attenuation }\end{array}$ & 46.62 & 48.44 & 49.89 & 48.41 \\
\hline
\end{tabular}

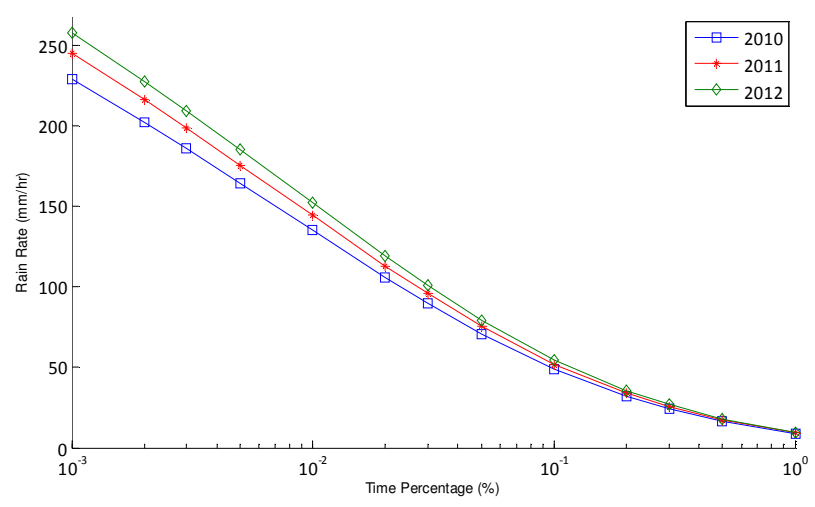

Figure 1: Cumulative rain rate distribution for Uyofor the years2010 to 2012.

From the results given in Table 2, it is seen that there has been a steady increase in rainfall accumulation for the three years under observation, which also inadvertently lead to a steady rise in rainfall rates. The average rainfall rate for Uyo is about $144 \mathrm{~mm} / \mathrm{hr}$. Similar work carried out in Ajayi and Ezekpo [23]puts the rainfall rate for Uyo at $125 \mathrm{~mm} / \mathrm{hr}$. Omotosho and Oluwafemi in [19] presented a value of $124 \mathrm{~mm} / \mathrm{hr}$ for Uyo. It should be noted that these two works were done with rain data collected over a 30-year period, and 9-year period respectively. The cumulative distribution shown in Figure 2 gives a comparison between this research work, Omotosho and ITU-R P.837-6 model. The ITU model gives the lowest value of $111.5 \mathrm{~mm} / \mathrm{hr}$. This is due to the fact that ITU measurements were carried out in temperate zones, hence give better performance within the temperate zones than in the tropics. A comparison performed with two years of rainfall data from Brazil concluded that the rain maps presented by ITU underestimated the rain rate cumulative distribution function for tropical zones[1]. According to Omotosho and Oluwafemi where locally measured data are not available, the ITU measurement may be used[19]. This is applicable only to the South West, South East, North West and North East regions of Nigeria.

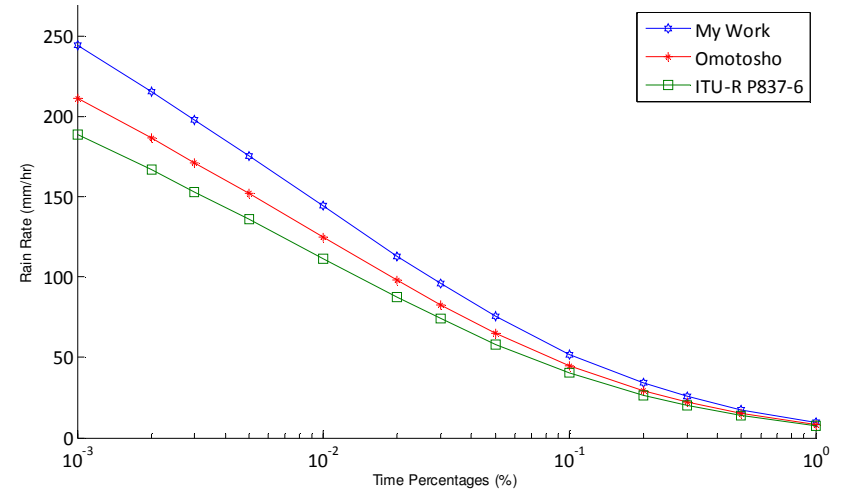

Figure 2: Comparison of rain rate distributions for Uyo

Table 3 shows the percentage mean bias error of the derived 1-minute rainfall rates with other works. Hence, a comparison of the three research works in Figure 3have similar results.

Table 3: Percentage mean bias error of the derived 1-

\begin{tabular}{lll}
\multicolumn{3}{c}{ minute rainfall rates with other works } \\
\hline ITU-RP837-6 mm/hr(A) & 111.49 \\
Omotosho mm/hr (B) & 124 \\
Ajayi-Ezekpo contour map data & 125 & \\
$\mathrm{~mm} / \mathrm{hr}(\mathrm{C})$ & 144.19 & \\
Present Work mm/hr (D) & (D - A)/D & 22.7 \\
\hline \multirow{3}{*}{$\%$ Mean Bias Error } & (D - B)/D & 14.0 \\
\cline { 2 - 3 } & (D - C)/D & 13.3 \\
\hline
\end{tabular}

\section{RAIN ATTENUATION DISTRIBUTION}

Rain attenuation distribution was obtained using the ITU rain attenuation model[ $[4,29,30]$. The cumulative distributions of rain attenuation were evaluated for Ka band with frequency $20 \mathrm{GHz}$ (downlink), elevation $54.5^{\circ}$, and a NIGCOMSAT 1 -R orbital position of $42.5^{\circ}$ $\mathrm{E}$, in order to meet today's active challenges in the rapid growth of satellite broadband networks. The Ka- 
band allows for a higher return link data rate. In order to obtain the rain attenuation at 0.001 to 0.1 percentage of the time exceeded, rain rate from each of the years in view, and the average rain rate was applied to the rain attenuation model in[4].

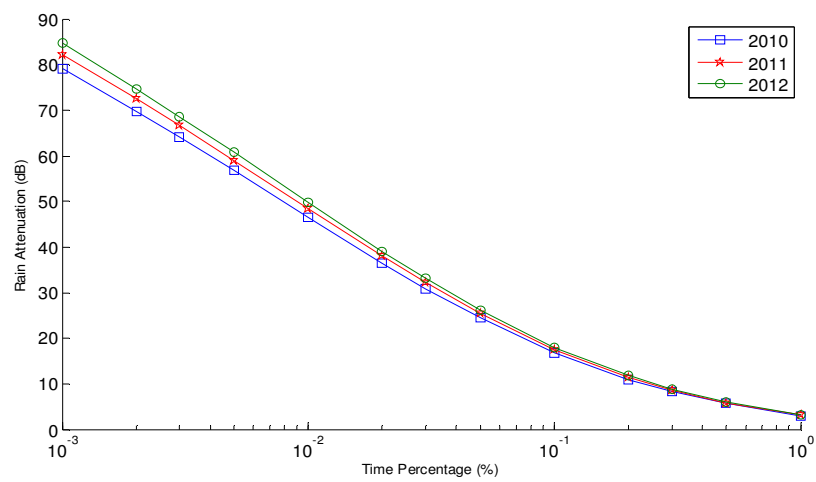

Figure 3: Cumulative Rain Attenuation Distribution for Uyo for the years2010 to 2012.

Table 2 shows the average rain attenuation measured over Uyo to be approximately $48 \mathrm{~dB}$ at a $0.01 \%$ of time exceeded. The cumulative distributions of rain attenuation for the three years are shown in Figure 3. It is observed that, the value of the $\mathrm{CDF}$ of rain attenuation for the three years at $48 \mathrm{~dB}$ may be considered very high for a system designer. However, this is seen to be consistent with the ITU which presents a measured value of about $41 \mathrm{~dB}$ for the same location.

\section{SEASONAL VARIATION OF RAIN RATE AND RAIN ATTENUATION}

In Nigeria, there are two major seasons - the dry season (between December and May) and the wet season (between June and November). For the purpose of our analysis, the dry season was further subdivided into driest (December to February), and early rain (March to May) months. The wet season was subdivided into heavy rainfall (June to August) and moderate rainfall (September to November) months. Rainfall accumulation, rain rate and rain attenuation for these seasons in each of the years were determined and the result is presented in Table 4.

From the result, as expected, rainfall accumulation was lowest between December and February for each of the three years: the year 2010 had the least rainfall by volume $(10.5 \mathrm{~mm})$, followed by $2012(77.4 \mathrm{~mm})$, while 2011 recorded the highest volume of rainfall $(86.0 \mathrm{~mm})$ for the driest months. The highest rainfall season was observed to be between June and August for all three years with rainfall accumulation as high as $2294 \mathrm{~mm}$ in 2012. The September to November season recorded moderately high rainfall volume for the three years.

The rain rate results also showed similar pattern. The lowest rain rate of $24.7 \mathrm{~mm} / \mathrm{hr}$ was obtained within the months of January, February and December 2010. The highest rain rates of $114.4 \mathrm{~mm} / \mathrm{hr}, 114.2 \mathrm{~mm} / \mathrm{hr}$ and $122.7 \mathrm{~mm} / \mathrm{hr}$ was obtained between June and August of the years 2010, 2011 and 2012 respectively. For seasonal rain attenuation, the lowest value was $15.3 \mathrm{~dB}$ in the driest months of January, February and December 2010. The highest rain attenuation (above $40 \mathrm{~dB}$ ) was gotten between June and August, followed by September to November season which recorded about $40 \mathrm{~dB}$ in 2011 and 2012. March to May had an average attenuation value of about $35 \mathrm{~dB}$ across the three years.

It could therefore be said that there would be more signal attenuation during the June to August season. Better signal quality will be experienced around December to February.

\section{CONCLUSION}

Rain rates and rain attenuation measurements for AKS using local data from the meteorology department of Uyo has been calculated for 99.999 to $99.9 \%$ availability of time. The refined Moupfouma model was used to obtain rain rate while the ITU-R P.618-11 model was used to obtain rain attenuation.

Table 4: Seasonal Variation of Rain Accumulation, Rain Rate and Rate Attenuation from 2010 to 2012

\begin{tabular}{|c|c|c|c|c|c|c|c|c|c|}
\hline \multirow[b]{2}{*}{ Month } & \multicolumn{3}{|c|}{2010} & \multicolumn{3}{|c|}{2011} & \multicolumn{3}{|c|}{2012} \\
\hline & $\begin{array}{c}\text { Rain } \\
\text { Volume } \\
(\mathrm{mm})\end{array}$ & $\begin{array}{l}\text { Rain Rate } \\
(\mathrm{mm} / \mathrm{h})\end{array}$ & $\begin{array}{c}\text { Rain } \\
\text { Attenua- } \\
\text { tion (dB) }\end{array}$ & $\begin{array}{c}\text { Rain } \\
\text { Volume } \\
(\mathrm{mm})\end{array}$ & $\begin{array}{c}\text { Rain Rate } \\
(\mathrm{mm} / \mathrm{h})\end{array}$ & $\begin{array}{c}\text { Rain } \\
\text { Attenua- } \\
\text { tion (dB) }\end{array}$ & $\begin{array}{c}\text { Rain } \\
\text { Volume } \\
(\mathrm{mm})\end{array}$ & $\begin{array}{l}\text { Rain Rate } \\
(\mathrm{mm} / \mathrm{h})\end{array}$ & $\begin{array}{c}\text { Rain } \\
\text { Attenua- } \\
\text { tion (dB) }\end{array}$ \\
\hline $\begin{array}{l}\text { Dec - } \\
\text { Feb }\end{array}$ & 10.5 & 24.7 & 15.3 & 86.0 & 46.2 & 23.8 & 488.6 & 77.4 & 33.3 \\
\hline $\begin{array}{l}\text { Mar - } \\
\text { May }\end{array}$ & 273.5 & 65.2 & 29.9 & 818.0 & 90.3 & 36.7 & 540.0 & 79.8 & 34.0 \\
\hline $\begin{array}{l}\text { Jun - } \\
\text { Aug }\end{array}$ & 1814.6 & 114.4 & 42.3 & 1803.4 & 114.2 & 42.3 & 2294.1 & 122.7 & 44.1 \\
\hline $\begin{array}{l}\text { Sep - } \\
\text { Nov }\end{array}$ & 636.9 & 83.8 & 35.0 & 1261.4 & 102.7 & 39.7 & 1328.3 & 104.3 & 40.0 \\
\hline
\end{tabular}


Results gotten show a high rain-rate and rainattenuation for a tropical rain zone like Uyo, which was to be expected. Comparisons with related works carried out by two other people and ITU[4] show similar trends. These results will be useful in the preliminary design for both terrestrial and earthsatellite links. This is because a system will have to be designed with a fade margin above $48 \mathrm{~dB}$. However, such a system might be very expensive; hence to be certain of the fade margin required, a reliable value of fade margin may be obtained through the analyses of a long-term data, such as a 7-year rainfall data. Furthermore, these analyses will provide a broad idea of rain attenuation to communication engineers for the design of link budget for improved signal propagation in this part of the Nigeria.

\section{ACKNOWLEDGEMENT}

The authors are grateful to the Management of the Akwa-Ibom International Airport, Uyo, Akwa-Ibom State, for providing access to the data used in this research work.

\section{REFERENCES}

[1]. Emiliani, L.D., et al., Development of rain-attenuation and rain-rate maps for satellite system design in the $\mathrm{Ku}$ and $\mathrm{Ka}$ bands in Colombia. Antennas and Propagation Magazine, IEEE, 2004. 46(6): p. 54-68.

[2]. Choi, D.Y., et al., Comparison of Measured Rain Attenuation in the $12.25 \mathrm{GHz}$ Band with Predictions by the ITU-R Model. International Journal of Antennas and Propagation, 2012. 2012: p. 5.

[3]. Salonen, E.T. and J.P.V. Poiares-Baptista. A new global rainfall rate model. in Proceedings of the 10th International Conference on Antennas and Propagation. 1997. Pub N 14-176-436.

[4]. Union, I.T., Propagation data and prediction methods required for the design of Earth-space telecommunication systems, in Recommendation ITU-R P.618-11, 2013, ITU Radiocommunication Sector (ITU-R).

[5]. Segal, B., The Influence of Raingage Integration Time, on Measured Rainfall-intensity Distribution Functions. Journal of Atmospheric and Oceanic Technology, 1986. 3(4): p. 662-671.

[6]. Crane, R.K. and A.W. Dissanayake, ACTS propagation experiment: attenuation distribution observations and prediction model comparisons. Proceedings of the IEEE, 1997. 85(6): p. 879-892.

[7]. Ojo, J.S., M.O. Ajewole, and S.K. Sarkar, Rain Rate and Rain Attenuation Prediction for Satellite Communication in $\mathrm{Ku}$ and $\mathrm{Ka}$ Bands over Nigeria.
Progress in Electromagnetics Research B, 2008. 5: p. 207-223.

[8]. Ajayi, G.O. and E.B.C. Ofoche, Some Tropical Rainfall Rate Characteristics at Ile-Ife for Microwave and Millimeter Wave Applications. Journal of Climate and Applied Meteorology, 1984. 23(4): p. 562-567.

[9]. Ibiyemi, T.S., et al. Rain rate and rain attenuation prediction with experimental rain attenuation efforts in south-western Nigeria. in Telecommunications Forum (TELFOR), $201220^{\text {th }}, 2012$.

[10].Obiyemi, 0.0. and T.S. Ibiyemi. Experimental investigation of rainfall effect on digital satellite television reception in Nigeria: Initial results. in Adaptive Science \& Technology (ICAST), 2014, IEEE 6th International Conference on. 2014.

[11].Obiyemi, O.O., J.S. Ojo, and T.S. Ibiyemi, Performance Analysis of Rain Rate Models for Microwave Propagation Designs Over Tropical Climate. Progress In Electromagnetics Research M, 2014. 39: p. 115122.

[12].Omotosho, T., et al. One year results of one minute rainfall rate measurement at Covenant University, Southwest Nigeria. in Space Science and Communication (IconSpace), 2013 IEEE International Conference on. 2013. IEEE.

[1]3.Semire, F.A., et al., Analysis of cumulative distribution function of 2-year rainfall measurements in Ogbomoso, Nigeria. International Journal of Applied Science and Engineering, 2012. 10(3): p. 171-179.

[14] Adimula, I., O. Falaiye, and A. Willoughby, Effects of rain on microwave and satellite communications in equatorial and tropical regions. Nigerian Journal of Physics, 2006. 17(1): p. 66-71.

[15] Union, I.T., Characteristics of Precipitation for Propagation Modeling, in Recommendations P837-6, ITU-R Recommendations, 2012, ITU Radiocommunication Sector (ITU-R).

[16].Crane, R.K., Comparative evaluation of several rain attenuation prediction models. Radio Sci., 1985. 20(4): p. 843-863.

[17] Dutton, E.J. and H.T. Dougherty, Year-to-year variability of rainfall for microwave applications in the USA. IEEE Transactions Communication, 1979: $\mathrm{p}$. Vol. 28, 829-832.

[18]. Chebil, J. and T.A. Rahman, Development of 1 min rain rate contour maps for microwave applications in Malaysia Peninsula. Electronics Letters, 1999: p. Vol. 35, 1712-1774.

[19]. Omotosho, T.V. and C.O. Oluwafemi, One-minute rain rate distribution in Nigeria derived from TRMM satellite data. Journal of Atmospheric and SolarTerrestrial Physics, 2009. 71(5): p. 625-633. 
[20]. Allnutt, J.E., E.B. Ojeba, and T.I. Raji, Results of 11.6 $\mathrm{GHz}$ radiometric experiment in Nigeria: second year. Electronics letters, 1994. 30(17): p. 1452-1453.

[21].Crane, R.K., Electromagnetic Wave Propagation Through Rain. null. Vol. null. 1996. null.

[22].Moupfouma, F. and L. Martin, Modelling of the Rainfall Rate Cummulative Distribution for the Design of Satellite and Terrestrial Communication Systems. Inernational Journal of Satellite Communications, 1995. 12(No 2): p. 105 - 115.

[23].Ajayi, G.O. and S.U.B. Ezekpo, Development of climatic maps of rainfall rate and attenuation for microwave applications in Nigeria. Nigeria Engineering Journal 23(4), 1988: p. 13-30.

[24].Rice, P. and N. Holmberg, Cumulative Time Statistics of Surface-Point Rainfall Rates. IEEE Transactions on Communications, 1973. 21(10): p. 1131-1136.

25. Ryde, J.W., The attenuation and radar echoes produced at centimetre wavelengths by various meteorological phenomena., in Meteorological Factors in Radio-wave Propagation, 1946, Physical Society: London, England. p. 169-188.

[26].Crane, R.K., Prediction of the effects of rain on satellite communication systems. Proceedings of the IEEE, 1977. 65(3): p. 456-474.

[27].Crane, R.K., A two-component rain model for the prediction of attenuation statistics. Radio Science, 1982. 17(6): p. 1371-1387.

[28].SG3, I.R.P., Study Group 3 Databanks, 2008.

[29].Union, I.T., Rain Height Model for Prediction Methods, in Recommendations ITU-R P.839-4, 2013, ITU Radiocommunication Sector (ITU-R).

[30].Union, I.T., Specific Attenuation Model for Rain for use in Prediction Methods, in Recommendations ITU-R P.838-3, 2005, ITU Radiocommunication Sector (ITU-R). 